\title{
Anti-neurotrophic effects from autoantibodies in adult diabetes having primary open angle glaucoma or dementia
}

\author{
Mark B. Zimering ${ }^{1,2}{ }^{*}$, Thomas E. Moritz ${ }^{3}$ and Robert J. Donnelly ${ }^{4}$ \\ ${ }^{1}$ Medical Service, New Jersey Health Care System, Department of Veterans Affairs, Lyons, NJ, USA \\ ${ }^{2}$ Robert Wood Johnson Medical School, University of Medicine and Dentistry of New Jersey, New Brunswick, NJ, USA \\ ${ }^{3}$ Cooperative Study Coordinating Center, Hines Veterans Hospital, Hines, IL, USA \\ ${ }^{4}$ Molecular Resource Facility, University of Medicine and Dentistry of New Jersey, New Jersey Medical School, Newark, NJ, USA
}

\section{Edited by:}

Maria Lopes-Virella, Medical

University of South Carolina, USA

Reviewed by:

Kay Waud, Eastern Virginia Medical School, USA

Undurti N. Das, UND Life Sciences, USA

\section{*Correspondence:}

Mark B. Zimering, Medical Service 111, Veterans Affairs New Jersey Healthcare System, Lyons, NJ 07939, USA.

e-mail: mark.zimering@va.gov

\begin{abstract}
Aim: To test for anti-endothelial and anti-neurotrophic effects from autoantibodies in subsets of diabetes having open-angle glaucoma, dementia, or control subjects.

Methods: Protein-A eluates from plasma of 20 diabetic subjects having glaucoma or suspects and 34 age-matched controls were tested for effects on neurite outgrowth in rat pheochromocytoma PC12 cells or endothelial cell survival. The mechanism of the diabetic glaucoma autoantibodies' neurite-inhibitory effect was investigated in co-incubations with the selective Rho kinase inhibitor Y27632 or the sulfated proteoglycan synthesis inhibitor sodium chlorate. Stored protein-A eluates from certain diabetic glaucoma or dementia subjects which contained long-lasting, highly stable cell inhibitory substances were characterized using mass spectrometry and amino acid sequencing.
\end{abstract}

Results: Diabetic primary open angle glaucoma (POAG) or suspects $(n=20)$ or diabetic dementia $(n=3)$ autoantibodies caused significantly greater mean inhibition of neurite outgrowth in PC12 cells $(p<0.0001)$ compared to autoantibodies in control diabetic $(n=24)$ or non-diabetic $(n=10)$ subjects without glaucoma $(p<0.01)$. Neurite inhibition by the diabetic glaucoma autoantibodies was completely abolished by $10 \mu \mathrm{M}$ concentrations of Y27632 $(n=4)$. It was substantially reduced by $30 \mathrm{mM}$ concentrations of sodium chlorate $(n=4)$. Peak, long-lasting activity survived storage $\times 5$ years at $0-4^{\circ} \mathrm{C}$ and was associated with a restricted subtype of Ig kappa light chain. Diabetic glaucoma or dementia autoantibodies $(n=5)$ caused contraction and process retraction in quiescent cerebral cortical astrocytes effects which were blocked by $5 \mu \mathrm{M}$ concentrations of $\mathrm{Y} 27632$.

Conclusion: These data suggest that autoantibodies in subsets of adult diabetes having POAG (glaucoma suspects) and/or dementia inhibit neurite outgrowth and promote a reactive astrocyte morphology by a mechanism which may involve activation of the RhoA/p160 ROCK signaling pathway.

Keywords: autoantibodies, diabetes mellitus, open angle glaucoma, dementia, neurite outgrowth

\section{INTRODUCTION}

Glaucoma is a chronic neurodegenerative disorder affecting retinal ganglion cells (RGC) and is a leading cause of blindness worldwide (Quigley, 2011). Glaucoma has been reported to increase in older adults with type 2 diabetes mellitus (Klein et al., 1994; Goldacre et al., 2012), and in certain populations having Alzheimer's dementia (Tamura et al., 2006), although the mechanisms for these associations are unclear. The aim of the present study was to test the hypothesis that autoantibodies having anti-endothelial and anti-neuronal effects increase in older adults with type 2 diabetes and primary open angle glaucoma (POAG). We examined 20 older adults with type 2 diabetes and glaucoma, 34 age-matched adults without glaucoma (24 diabetic and 10 non-diabetic subjects), and 5 adults having diabetes and dementia for plasma autoantibodies which could inhibit neurite outgrowth in PC12 cells or decrease endothelial cell (EC) survival.
Humoral autoimmunity has been implicated in the etiology of certain forms of glaucoma (Tezel and Wax, 2004) including evidence for increased circulating autoantibodies to optic nerve head heparan sulfate proteoglycans (HSPG) in subsets of normal tension or POAG (Tezel et al., 1999). Anti-neuronal HSPG autoantibodies (having anti-neuronal and anti-endothelial effects) were reported in adult type 2 diabetes in association with certain microvascular complications including painful neuropathy (Zimering et al., 2011). The diabetic neuropathy plasma IgG autoantibodies induced EC contraction, EC apoptosis, and inhibited neurite outgrowth through a mechanism involving activation of the Rho $\mathrm{A} / \mathrm{Rho}$ kinase signaling pathway (Zimering and Pan, 2009; Zimering et al., 2011). The Rho A/Rho kinase signaling pathway is present in diverse cell types (neurons, astrocytes, and endothelial-like trabecular meshwork cells) implicated in the pathophysiology of glaucoma (Tura et al., 2009; Kumar 
and Epstein, 2011; Kameda et al., 2012). Our hypothesis is that autoantibodies capable of binding to HSPG expressed on neurons, astrocytes, and ECs and activating Rho A/Rho kinase signaling may be capable of mediating axonal injury, ischemia, and glial reactivity underlying early glaucomatous changes (Crish and Calkins, 2011) leading to vision loss.

We now report that plasma IgG autoantibodies from diabetic POAG or suspects $(n=20)$ significantly inhibited neurite outgrowth in PC12 cells $(p<0.0001)$ compared to autoantibodies from diabetic $(n=24)$ or non-diabetic $(n=10)$ subjects without glaucoma. The neurite outgrowth inhibitory activity in four of four diabetic (POA) glaucomatous plasma autoantibodies tested was completely abolished by co-incubating PC12 cells with $10 \mu \mathrm{M}$ concentrations of Y27632, a selective Rho kinase inhibitor. The neurite-inhibitory activity was also significantly reduced in the presence of $30 \mathrm{mM}$ sodium chlorate which substantially reduces HSPG expression in PC12 cells. Taken together, these data suggest possible involvement of cell surface HSPG and activation of the Rho A/Rho kinase signaling pathway in the mechanism for PC12 neurite inhibition by diabetic glaucoma plasma autoantibodies.

\section{MATERIALS AND METHODS \\ SUBJECTS}

Informed consent for the Investigational Review Board (IRB) approved substudy to the Veterans Affairs Diabetes Trial (VADT) was obtained from all subjects. Fifteen of 89 subjects enrolled at the VA New Jersey Healthcare System (VANJHCS) study site to the VADT had a diagnosis of POAG or glaucoma suspect. Eleven of the 15 VADT subjects were included in the study based on the availability of an aliquot of plasma stored at $-70^{\circ} \mathrm{C}$ necessary for protein-A affinity chromatography to obtain IgG autoantibodies. The four excluded subjects included two non-Hispanic white glaucoma subjects, one African-American glaucoma suspect and one non-Hispanic white glaucoma suspect. A control group of 21 VADT subjects without glaucoma or suspicion of glaucoma was randomly selected from among the remaining patients in whom baseline plasma was available for analysis. Twenty-two additional diabetic or non-diabetic glaucoma subjects or controls all evaluated in an IRB-approved VANJHCS study were selected for further analysis of the association between diabetic POAG and plasma autoantibodies.

\section{DIAGNOSTIC METHODS AND SUBGROUPS \\ Glaucoma or suspects}

All subjects were evaluated by the optometry and/or ophthalmology staff at the Veterans Affairs New Jersey Healthcare System. The diagnosis of POAG was based on findings from a combination of test modalities including: dilated fundoscopic examination, applanation tonometry, gonioscopy, pachymetry, periodic Humphrey visual field testing, or the results of Humphrey visual field tests, dilated fundoscopic examination, and tonometry performed by outside ophthalmologists and reported to optometry/ophthalmology specialists at the VANJHCS. Glaucoma suspect is defined as a high risk individual with asymmetric cup to disk (C/D) enlargement, equivocal neural rim narrowing, or retinal nerve fiber layer thinning, but without definite evidence for visual field loss. Subjects with increased intraocular pressure (IOP) alone, but without $\mathrm{C} / \mathrm{D}$ enlargement were not included in the primary analysis, e.g., ocular hypertension $(n=1)$. Because many patients were already being treated with IOP-lowering medications at the time of study enrollment, it was not possible to distinguish subgroups of normal tension glaucoma vs. high-pressure POAG. Patients with secondary forms of glaucoma such as neovascular glaucoma $(n=1)$, or corticosteroid-associated glaucoma $(n=1)$ were excluded from the analysis. Subjects with other ocular or neuropathologies previously associated with potent EC autoantibodies, but lacking diabetic painful neuropathy, e.g., central retinal artery occlusion $(n=1)$, dementia $(n=1)$, or stroke $(n=1)$ were excluded from the analysis. Painful diabetic neuropathy was defined as the presence of characteristic findings on clinical examinations performed by expert neurologists as previously reported (Zimering et al., 2011). Diabetic nephropathy was defined as urinary albumin excretion $\geq 300 \mathrm{mg} / \mathrm{g}$ creatinine or urinary protein excretion $\geq 500 \mathrm{mg} / \mathrm{g}$ creatinine.

\section{Diabetes and dementia $(n=3+2)$}

In three VADT patients who developed dementia at the end of the clinical trial, neurite-inhibitory activity in PC12 cells was analyzed (Figure 1) as a control for the results in glaucoma, another type of chronic neurodegenerative disorder. Patient \#1 was a 68year-old African-American male with POAG, long-standing type 2 diabetes without significant diabetic retinopathy who was diagnosed with glaucoma at the onset of his VADT participation. His mild visual field loss was stable over a 7-year observation period; he was diagnosed with Alzheimer's type dementia. Patient \#2 is a 71 year old non-Hispanic white male with type 2 diabetes, ocular hypertension without baseline visual field loss whose visual fields were stable and cup/disk ratio was normal over a 5-year observation period; he was diagnosed with dementia secondary to traumatic brain injury. Patient \#3 was a 75 -year-old nonHispanic white male with long-standing type 2 diabetes, no evidence of glaucoma, and mixed fronto-temporal and multi-infarct dementia.

Two additional subjects having diabetes and dementia were included in the analysis of EC inhibitory activity in stored proteinA eluates (Table 3). Patient \#4 is a 70-year-old VADT subject who had type $2 \mathrm{DM}$, mild diabetic retinopathy, and later developed Alzheimer's type dementia. Patient \#5 is a 53-year-old type 1 DM (non-VADT) patient who had a wide spectrum of microvascular complications including nephropathy leading to end stage renal disease, multiple recurrent small vessel strokes (Zimering, 2010) progressing to dementia, proliferative diabetic retinopathy, autonomic and painful neuropathy, and glaucoma possibly due to steroid use.

\section{Blood drawing}

Baseline plasma samples were obtained from study subjects prior to initiation of treatment in the VADT substudy. Plasma bFGF was determined with a sensitive specific two-site IRMA as previously described (Zimering et al., 2009a). Bioactivity in protein-A eluate fractions was previously shown to be stable for 5 years or longer at $-20^{\circ} \mathrm{C}$ (Zimering and Thakker-Varia, 2002). 


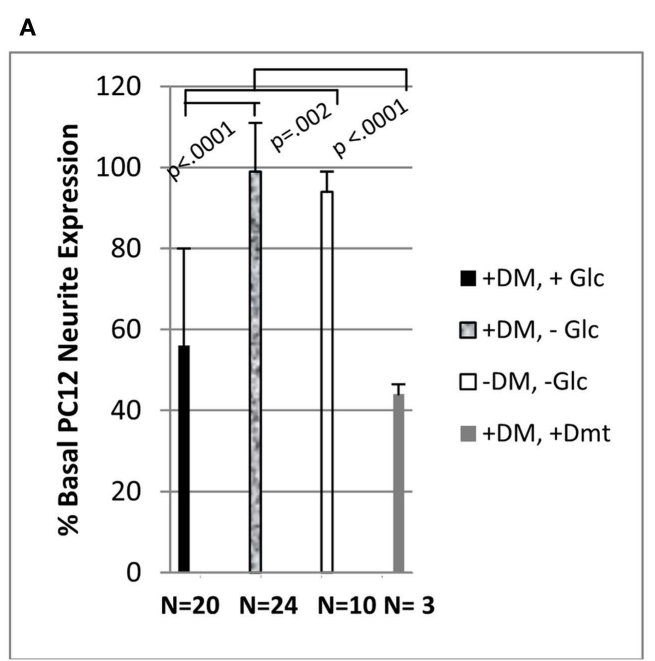

C

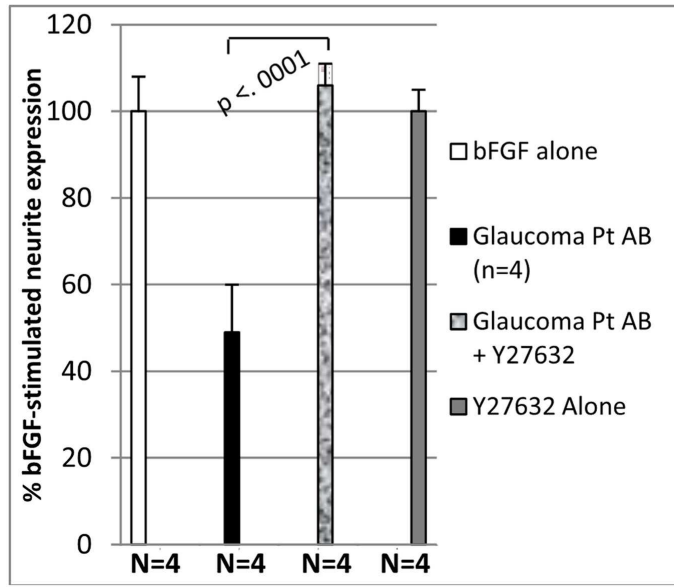

FIGURE 1 | Diabetic glaucomatous autoantibodies inhibit neurite expression in PC 12 cells (A) highest neurite-inhibitory activity was associated with glaucomatous vision loss (B) and was eliminated by treatment with Y27632 (C) or $30 \mathrm{mM}$ sodium chlorate (D). (A-D) Thirty microgram per milliliter concentrations of the protein-A eluate fraction of plasma was incubated with PC12 cells in the presence or absence of $10 \mu \mathrm{M}$

\section{Neurite outgrowth inhibition assay}

Undifferentiated rat pheochromocytoma PC12 cells obtained from ATCC (Manassa, VA, USA) were grown in DMEM containing $10 \%$ horse serum, $5 \%$ fetal calf serum, and $10 \mathrm{ng} / \mathrm{mL}$ bFGF was added in order to induce neuronal differentiation. Test proteinA eluate fractions (1:50 dilution $=30 \mu \mathrm{g} / \mathrm{mL}$ protein $)$ were added to cells in duplicate or triplicate and incubated at $37^{\circ} \mathrm{C}$ for $48 \mathrm{~h}$. Next the proportion of cells expressing a neurite of $\geq 2$ cell diameters in length was counted and compared to the proportion of bFGF-stimulated neurite cell expression in dishes containing bFGF without added test fractions as previously described (Zimering et al., 2011). Rho kinase-dependence of the neurite inhibition was assessed by co-incubating cells in the presence or absence of $10 \mu \mathrm{M}$ concentrations of Y27632, a selective inhibitor for the Rho-associated protein kinase, p160ROCK (Uehata et al., 1997).
B

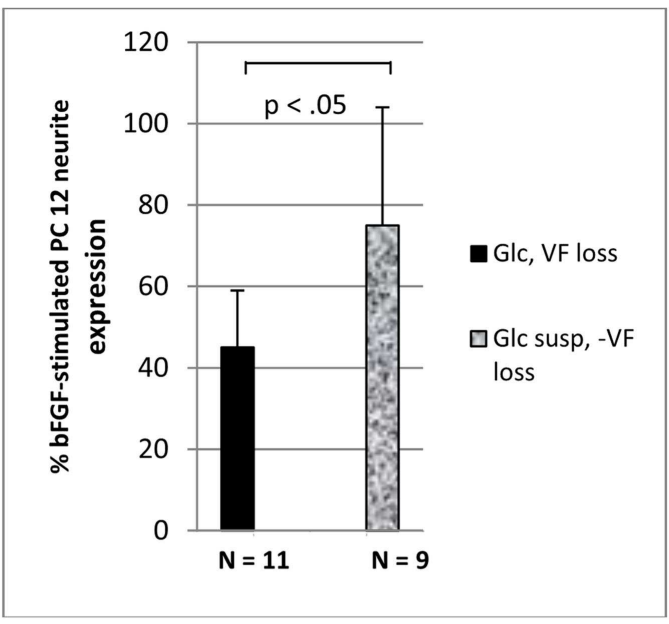

D

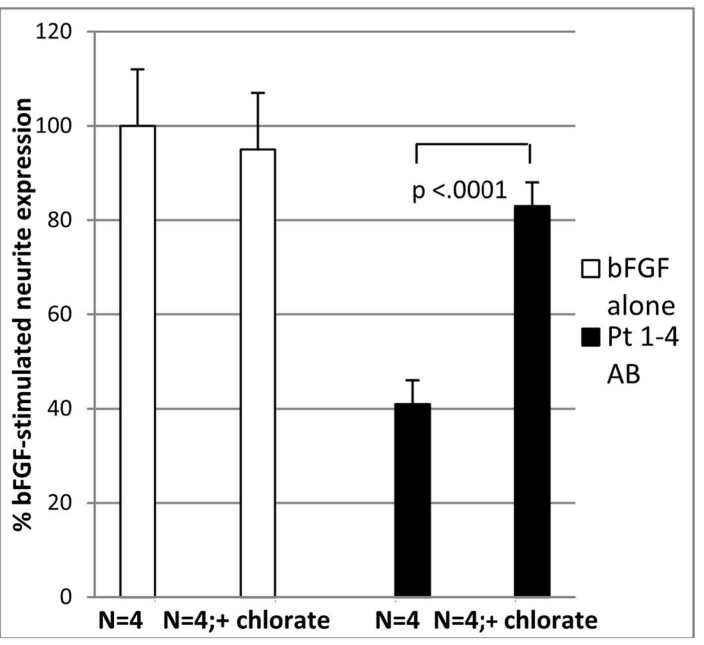

concentrations of Y27632 (C) or $30 \mathrm{mM}$ concentrations of sodium chlorate (D) as described in Section "Materials and Methods." Results (mean \pm 1 SD of four different protein-A eluates) are expressed as \% neurite expression compared to cells incubated with $10 \mathrm{ng} / \mathrm{mL}$ concentrations of basic fibroblast growth factor alone [i.e., 100\%, open bars (C,D)]. DM, diabetes mellitus; Glc, glaucoma or suspect (susp); Dmt, dementia; VF, visual field.

Dependence of neurite-inhibitory effects in the diabetic proteinA eluates on cell surface sulfated proteoglycans was tested by comparing results in to pheochromocytoma PC12 cells grown in the presence or absence of $30 \mathrm{mM}$ sodium chlorate, a treatment which substantially reduces HSPG expression in the cells (Hoogewerf et al., 1991).

\section{Endothelial cell survival assay}

Bovine pulmonary artery ECs (Clonetics, Inc., San Diego, CA, USA) were grown in Medium 199 plus $10 \%$ fetal calf serum and EC growth medium (EGM, Clonetics, Inc., San Diego, CA, USA). EC survival in the presence or absence of diabetic plasma protein-A eluates $(30 \mu \mathrm{g} / \mathrm{mL})$ was assessed after $48 \mathrm{~h}$ incubation as previously described (Zimering et al., 2011). Results represent the mean $( \pm 1$ SD) of quadruplicate determinations. 


\section{Human lymphoblast cell culture}

Human lymphoblasts (GM 01500) from a patient having light chain amyloidosis (AL disease) were obtained from the Human Mutant Repository, Coriell Institute (Camden, NJ, USA), and grown in RPMI 1640 containing 2 mM L-glutamine, 10\% fetal calf serum. The cell supernatant was subjected to sequential proteinA affinity chromatography followed by antihuman IgG affinity chromatography in order to obtain partially purified monoclonal human IgG for testing of EC bioactivity.

\section{Protein-A affinity chromatography}

The IgG fraction of plasma was isolated using protein-A affinity chromatography as previously reported (Zimering et al., 2011).

\section{Antihuman IgG affinity chromatography}

The protein-A eluate fraction obtained after applying $1.0 \mathrm{~mL}$ of the human lymphoblast (GM 01500) cell supernatant to a protein-A affinity column $(1.0 \mathrm{~mL})$ was adjusted to $\mathrm{pH} 7.0$ by adding $1 \mathrm{M}$ Tris $\mathrm{pH}$ 9.0. The eluate was then diluted 1:1 with an equal volume of $100 \mathrm{mmol} / \mathrm{L}$ Tris $\mathrm{pH} 8.0$ and applied to a goat antihuman IgG agarose column $(1.0 \mathrm{~mL})$, washed with $5 \mathrm{~mL}$ of $100 \mathrm{mmol} / \mathrm{L}$ Tris $\mathrm{pH} 8.0$, and eluted stepwise with $5 \times 1.0 \mathrm{~mL}$ aliquots of $100 \mathrm{mmol} / \mathrm{L}$ sodium citrate, $\mathrm{pH}$ 3.0. The second eluate fraction contained nearly all of the recovered protein and it was adjusted to $\mathrm{pH} 7.0$ with $1 \mathrm{M}$ Tris $\mathrm{pH} 9.0$ prior to sterile filtration and testing of biological activity.

\section{Cerebral cortical astrocytes}

Rat cerebral cortices were dissociated and placed in polylysinecoated T-75 flasks containing minimal essential medium without phenol red and 15\% fetal bovine serum (having low estradiol concentration)-NM-15. They were fed on day 3 with fresh NM-15 medium. On day 10, the flasks were shaken overnight at $250 \mathrm{rpm}$. The next day, the medium was removed, the cells were rinsed with warm PBS, and then fresh NM-15 containing $10 \mathrm{mM}$ AraC was added to the cells. Two days later, the cells were trypsinized and plated at 250,000 cells per dish in polylysine-coated $35 \mathrm{~mm}$ dishes containing NM-15. After 2-3 weeks in serum-containing medium, a small percentage of the astrocytes (1-5\%) spontaneously differentiated from a flat polygonal shape into cells having a "stellate" appearance, bearing one or more thick processes located proximal to the cell body or several thin long branching processes located distal to the cell body. The acute effects of diabetic plasma autoantibodies on astrocyte morphology were assessed in cells that had been maintained for 2-3 weeks in culture. Cell viability was good under these long-term culture conditions.

\section{Time-lapse photomicroscopy}

Stellate-appearing astrocytes (and surrounding less differentiated cells) were imaged under high power magnification using a Nikon TMS microscope at $200 \times$ magnification. Following bath application of a 1:100 dilution $(3-20 \mu \mathrm{g} / \mathrm{mL})$ of protein-A eluates from diabetic glaucoma or control subjects, cells were observed continuously for acute change in morphology. Baseline and follow-up images were captured using a Nikon camera connected to the microscope with a phototube every $5 \mathrm{~min}$ for a period up to 30-45 min after addition of protein-A eluates.

\section{Heparin Sepharose affinity chromatography}

Heparin Sepharose (HS) affinity chromatography was carried out as previously reported (Zimering et al., 2009a).

\section{SELDI mass spectrometry}

Mass spectrometry was carried out as previously reported (Zimering et al., 2011).

\section{Protein sequencing}

Amino acid sequencing was carried out on the Applied Biosystems (Foster City, CA, USA) Procise ${ }^{\circledR} 494$ protein sequencer using standard Edman sequencing. The resulting chromatographs were analyzed using Model 610A software.

\section{Furin digests of diabetic protein-A eluates}

Two microliters of an aqueous solution containing human recombinant furin ( $\geq 2000$ units $/ \mathrm{mL}$ ) was added to $40 \mu \mathrm{L}$ of protein-A eluates ( $8 \mu \mathrm{g}$ protein) from each of three diabetic subjects in buffer containing $100 \mathrm{mmol} / \mathrm{L}$ Tris, $\mathrm{pH} 7.0$, and $200 \mu \mathrm{M}$ calcium. Following $180 \mathrm{~min}$ incubation at $25^{\circ} \mathrm{C}, 4 \mu \mathrm{L}$ aliquots of furin-treated or -untreated protein-A eluates were added in quadruplicate to ECs for testing of biological activity. The remaining aliquot of furin-treated and -untreated paired samples was subjected to mass spectrometry which revealed a decrease in the peak $23 \mathrm{kDa}$ apparent light chain MW species (present in untreated samples) in paired samples subjected to furin digestion.

\section{Chemicals}

Protein-A agarose was obtained from Pierce Chemical Co. (Rockford, IL, USA). Goat antihuman IgG (whole molecule) agarose was obtained from Sigma Chemical Co. (St. Louis, MO, USA). Human recombinant furin was obtained from Sigma Chemical Co. (St. Louis, MO, USA). All other chemicals and reagents were analytical grade.

\section{Protein determinations}

Protein concentrations were determined by a bicinchoninic acid protein assay kit (Pierce Chemical Co., Rockford, IL, USA).

\section{Statistics}

All data are the mean $\pm 1 \mathrm{SD}$ as indicated. Comparisons were made by paired and unpaired Student's $t$-tests, or Fischer's exact test as indicated.

\section{RESULTS ASSOCIATION BETWEEN DIABETIC GLAUCOMA OR GLAUCOMA SUSPECT AND RACE}

Diabetic subjects with POAG or POAG suspects included a significantly higher proportion of African-American or subjects of Afro-Caribbean descent compared to diabetes without glaucoma (Table 1). Mean baseline diastolic blood pressure was significantly higher in diabetes having POAG or suspects than in diabetes without glaucoma (Table 1). It was also higher in a control group of non-diabetic subjects without glaucoma (Table 1). There was a trend of a significant association $(p=0.06)$ between low plasma basic fibroblast growth factor $(0-3.4 \mathrm{pg} / \mathrm{mL})$ and an increased proportion of diabetic subjects having POAG or suspects vs. no POAG or suspect (100 vs. $69 \%$; Table 1 ). 
Table 1 | Baseline clinical characteristics in the study subjects.

\begin{tabular}{|c|c|c|c|c|}
\hline \multirow[t]{2}{*}{ Risk factor } & \multicolumn{3}{|c|}{ Diabetes } & \multirow{2}{*}{$\begin{array}{l}\text { No diabetes } \\
\text { No Glc } \\
(N=10)\end{array}$} \\
\hline & $\begin{array}{l}\text { No Glc } \\
(N=24)\end{array}$ & $\begin{array}{l}\text { Glc or susp } \\
(N=20)\end{array}$ & $P$-value* & \\
\hline Age (years) & $65.2 \pm 8.3$ & $69.6 \pm 12.3$ & 0.16 & $68.0 \pm 16.7$ \\
\hline Race (NHW/AA/H) & $(22 / 1 / 1)$ & $(9 / 10 / 1)$ & $0.0006^{\wedge}$ & $(5 / 4 / 1)$ \\
\hline BMI $\left(k g / m^{2}\right)$ & $32.0 \pm 5.1$ & $32.0 \pm 6.9$ & 0.99 & $31.2 \pm 7.7$ \\
\hline DM duration (years) & $11.0 \pm 6.9$ & $13.9 \pm 10.0$ & 0.28 & NT \\
\hline $\mathrm{Hba}_{1} \mathrm{c}(\%)$ & $8.3 \pm 1.4$ & $8.3 \pm 1.5$ & 0.95 & NT \\
\hline Syst bp (mm Hg) & $129.9 \pm 10.9$ & $133 \pm 13.6$ & 0.48 & $124 \pm 7.4$ \\
\hline Diast bp (mm Hg) & $67.6 \pm 8.9$ & $74.6 \pm 9.1$ & 0.01 & $76 \pm 7.0^{a}$ \\
\hline Total Chol (mg/dL) & $172 \pm 14$ & $176 \pm 41$ & 0.78 & $174 \pm 51$ \\
\hline Low bFGF (\%) & $69(16)$ & $100(11)$ & $0.06^{\wedge}$ & NT \\
\hline Insulin use (\%) & 39 & 60 & $0.18^{\wedge}$ & NT \\
\hline
\end{tabular}

Results are mean \pm 1 SD or proportion; (), number tested; Glc, glaucoma; susp, suspect; bp, blood pressure; Chol, cholesterol; Low bFGF, basic fibroblast growth factor $=<4 \mathrm{pg} / \mathrm{mL}$; ^ Fischer's exact test; ${ }^{*} P$-value for comparison of diabetics with or without glaucoma. NHW, non-Hispanic white, AA, African-American, $H$, Hispanic, ${ }^{a} P=0.016$ compared to diabetes without glaucoma.

\section{ASSOCIATION BETWEEN DIABETIC GLAUCOMA (SUSPECT) AND PAINFUL NEUROPATHY OR FAMILY HISTORY OF DEMENTIA}

Low plasma basic fibroblast growth factor was associated with a significantly increased occurrence of EC inhibitory autoantibodies in older adult type 2 diabetes from the VADT (Zimering et al., 2009a). Since baseline EC inhibitory autoantibodies predicted an increased risk for certain microvascular complications in the VADT substudy (Zimering et al., 2009b), we tested for associations between diabetic POAG and EC inhibitory autoantibodies or co-morbid diabetic microvascular complications. A significantly higher proportion of diabetic subjects with POAG or suspects (65 vs. 25\%) had inhibitory EC autoantibodies compared to the proportion of diabetic subjects without glaucoma ( $p=0.014$; Table 2$)$. Painful neuropathy was significantly more prevalent among diabetic POAG or suspects compared to diabetes without POAG $(p=0.014$; Table 2$)$. First-degree relatives (mother, father) of diabetic POAG or suspects were significantly more likely to have had Alzheimer's dementia as a contributory cause of death compared to the parents of diabetic subjects without glaucoma (3/11 vs. $0 / 20 ; p=0.04$, Table 2 ).

\section{NEURITE OUTGROWTH INHIBITORY ACTIVITY IN DIABETIC PROTEIN-A ELUATES: ASSOCIATION WITH GLAUCOMATOUS VISION LOSS OR DEMENTIA}

Mean PC12 neurite outgrowth inhibitory activity in the protein-A eluates ( $1: 50$ dilution; $\sim 30 \mu \mathrm{g} / \mathrm{mL}$ ) of plasma from diabetic POAG or suspects significantly exceeded mean inhibitory activity from diabetes without glaucoma (55.7 \pm 24 vs. $99.0 \pm 12 \% ; p<0.0001$; Figure 1A). It was also significantly more inhibitory $(p=0.002)$ compared to mean activity in protein-A eluates from subjects without diabetes and without glaucoma ( $94.2 \pm 5 \%$; Figure 1A). The protein-A eluates of three diabetic subjects who later developed dementia had the most potent mean neurite-inhibitory activity $(44 \pm 3 \%)$. It significantly exceeded mean inhibitory activity in
Table 2 | Association between diabetic glaucoma or suspect and co-morbid microvascular complications or family history of dementia.

\begin{tabular}{|c|c|c|c|}
\hline \multirow[t]{2}{*}{ Risk factor } & \multicolumn{3}{|c|}{ Diabetes } \\
\hline & $\begin{array}{l}\text { No Glc } \\
(N=24)\end{array}$ & $\begin{array}{l}\text { Glc or susp } \\
(N=20)\end{array}$ & $\boldsymbol{P}$-value* \\
\hline ME, AMD (\%) & 12.5 & 30 & 0.26 \\
\hline Nephropathy (\%) & 25 & 15 & 0.48 \\
\hline Painful neuropathy (\%) & 25 & 65 & 0.014 \\
\hline Inhibitory EC Act ${ }^{\mathrm{C}}(\%)$ & 25 & 65 & 0.014 \\
\hline FH of dementia (\%) & $0(20)$ & $27(11)$ & 0.04 \\
\hline
\end{tabular}

Results are proportion; (), number tested; Glc, glaucoma, susp, suspect, *Fischer's exact test, comparison of diabetics with or without glaucoma; ME, macular edema, $A M D$, age-related macular degeneration, $F H$, family history in a $1^{\circ}$ relative of Alzheimer's dementia; ' significant inhibitory endothelial cell (EC) activity, defined as $\leq 90 \%$ of basal cell number as described in Section "Materials and Methods."

IgG from diabetes without glaucoma ( $p<0.0001$, Figure 1A). Diabetic glaucomatous vision loss $(n=11$ subjects $)$ was associated with significantly more inhibitory mean PC 12 neurite activity compared to mean activity in the protein-A eluates from nine diabetic POAG suspects $(45.5 \pm 14$ vs. $74.6 \pm 31 ; p<0.05$; Figure 1B).

\section{EFFECT OF RHO KINASE INHIBITOR ON NEURITE-INHIBITORY ACTIVITY IN DIABETIC PLASMA PROTEIN-A ELUATES}

The Rho A/Rho kinase signaling pathway plays an important role in axonal pathfinding during development (Dickson, 2001). Y27632 is a selective inhibitor of Rho kinase (Ishizaki et al., 2000). Diabetic glaucomatous plasma autoantibodies $(30 \mu \mathrm{g} / \mathrm{mL})$ from four African-American patients having moderate or severe progressive glaucomatous visual loss caused significant inhibition of neurite outgrowth in PC 12 cells (Figure 1C). The mean inhibitory activity from the four protein-A eluates was significantly reduced $(p<0.001)$ by co-incubating PC12 cells with $10 \mu \mathrm{M}$ concentrations of Y27632 (Figure 1C). Similar concentrations of Y27632 alone had no significant effect on PC12 cell neurite expression compared to cells exposed to bFGF $(10 \mathrm{ng} / \mathrm{mL})$ without Y27632 (Figure 1C).

\section{EFFECT OF REDUCED SULFATED PROTEOGLYCAN EXPRESSION IN PC 12 CELLS}

Sodium chlorate substantially reduces the sulfation of proteoglycans in various cells (Hoogewerf et al., 1991). To test for possible involvement of sulfated proteoglycan (e.g., HSPG) in the mechanism for neurite inhibition in diabetic glaucomatous plasma protein-A eluates, PC12 cell cultured in the presence or absence of $30 \mathrm{mM}$ sodium chlorate were incubated with the protein-A eluate fractions $(30 \mu \mathrm{g} / \mathrm{mL})$ of plasma from four diabetic subjects with POAG. The mean neurite-inhibitory activity in all four proteinA eluates (Pt 1-4 AB) (assayed individually) was significantly reduced $(P<0.0001)$ in the PC12 cells cultured in the presence of $30 \mathrm{mM}$ sodium chlorate compared to PC12 cells grown in standard medium (DMEM with 1\% FCS) in the absence of chlorate 
ion (solid bars, Figure 1D). PC12 cell viability was unaffected by the presence of $30 \mathrm{mM}$ chlorate. Neurite expression did not differ significantly in cells grown in the presence of bFGF with or without $30 \mathrm{mM}$ chlorate (open bars, Figure 1D).

\section{EFFECT OF DIABETIC PLASMA (POA) GLAUCOMATOUS AUTOANTIBODIES ON ASTROCYTE MORPHOLOGY}

Astrocytes play critical role(s) in maintenance of the blood-brain barrier (Allen et al., 2010), protect neurons against glutamateinduced excitotoxicity, and modulate blood flow to actively firing neurons. To facilitate these important neuronal support roles, astrocyte processes lie in close apposition to basement membranes, capillaries, and neuronal synapses. Since the expression of astrocytic processes, or stellation, is inhibited by activity in the
RhoA/Rho kinase signaling pathway (Abe and Misawa, 2003), we next tested whether autoantibodies from diabetic POAG or control subjects could inhibit astrocyte stellation in vitro. Plasma autoantibodies $(1: 100$ dilution $=3-20 \mu \mathrm{g} / \mathrm{mL})$ from five of five diabetic glaucoma or suspects tested ( $n=8$ experiments) caused retraction of thick processes located proximal to the astrocyte cell body (e.g., Figures 2A,B). Withdrawal of proximally located processes was most rapid (occurring within $2-5 \mathrm{~min}$ ) and more extensive leading to disruption connectivity among processes in neighboring cells after bath application of low concentration $(3 \mu \mathrm{g} / \mathrm{mL})$ of diabetic POAG plus dementia autoantibodies (Figures 2C,D). The retraction of thick astrocytic processes (induced by diabetic glaucoma + dementia autoantibodies) was prevented by pretreating cells (for $10 \mathrm{~min}$ ) with $5 \mu \mathrm{M}$ concentrations of $\mathrm{Y} 27632$

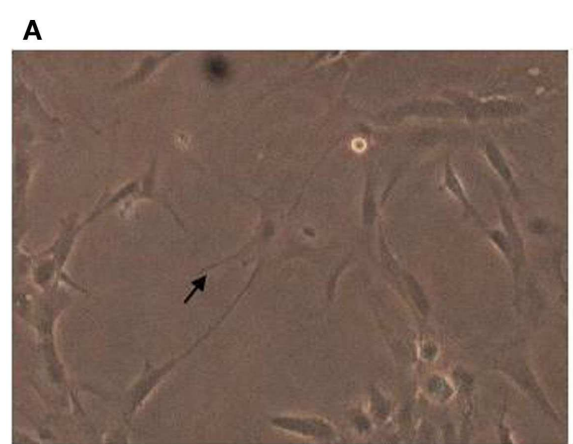

B

C

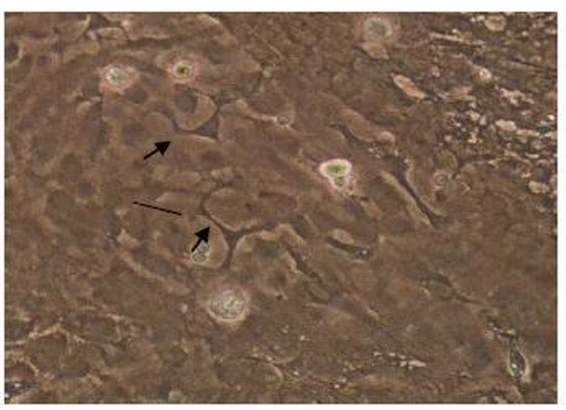

$\mathbf{E}$

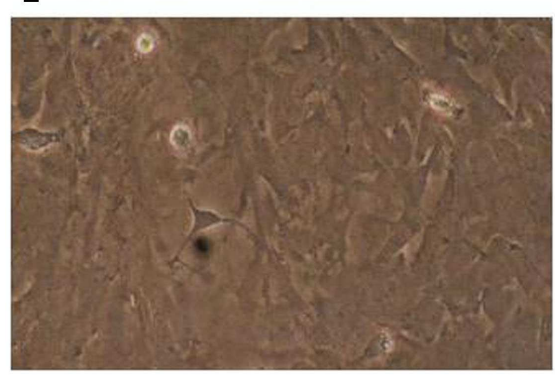

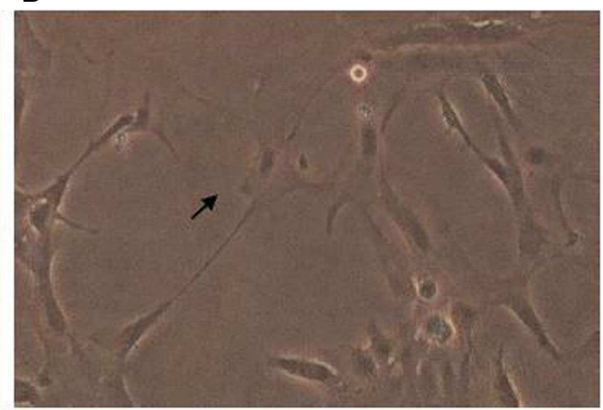

D

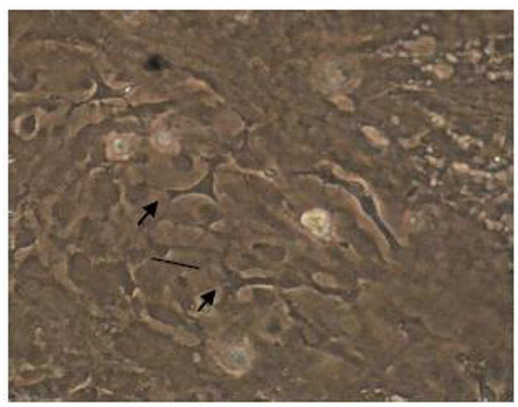

$\mathbf{F}$

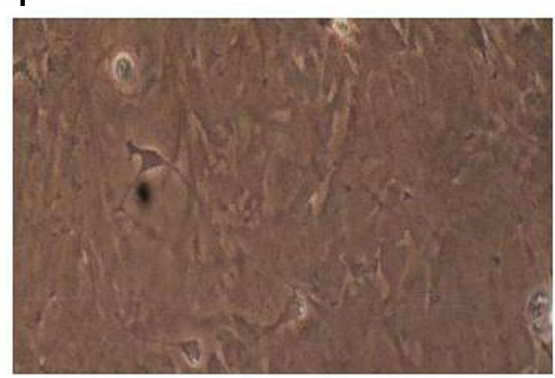

FIGURE 2 | Effect of diabetic glaucomatous autoantibodies on astrocyte morphology. Morphology in cerebral cortical astrocytes (A) before or (B) $30 \mathrm{~min}$ after addition of $10 \mu \mathrm{g} / \mathrm{mL}$ concentration of protein-A eluate from type $2 \mathrm{DM}$ and glaucoma; (C) before or (D) $10 \mathrm{~min}$ after addition of $3 \mu \mathrm{g} / \mathrm{mL}$ concentration of the protein-A eluate fraction from type 2 DM having glaucoma and Alzheimer's type dementia (Pt 1). Antibodies caused varying degrees of withdrawal of thick astrocyte processes associated with increased stress fiber expression (arrows), and cell contraction (vertical lines).
Astrocytes cultured in the presence of $10 \mu \mathrm{M}$ concentrations of $\mathrm{Y} 27632$ for 10 min before $(\mathbf{E})$ and after $(\mathbf{F})$ addition of a $3 \mu \mathrm{g} / \mathrm{mL}$ concentration of the Pt 1 protein-A eluate fraction did not undergo similar changes in their appearance. Results similar to those shown in (A-D) were obtained in eight experiments using $3-10 \mu \mathrm{g} / \mathrm{mL}$ concentrations of autoantibodies from five different diabetic glaucoma patients. Much less if any acute change in morphology was observed ( $n=4$ experiments) using $10-20 \mu \mathrm{g} / \mathrm{mL}$ concentrations of protein-A eluate from four type 2 DM subjects without glaucoma. 
(Figures 2E,F; $n=2$ experiments). Y27632 alone had no effect on astrocyte morphology (not shown in Figure 2). Control plasma autoantibodies $(10-20 \mu \mathrm{g} / \mathrm{mL})$ from four of four age-matched, non-diabetic subjects without glaucoma (or suspicion of glaucoma) tested had little or no significant effect on the morphology of astrocyte thick processes ( $n=4$ experiments, not shown in Figure 2). The active autoantibodies $(10-20 \mu \mathrm{g} / \mathrm{mL})$ from two of the diabetic glaucoma subjects that caused retraction of thick astrocyte processes had no apparent significant effect on morphology of thinner more distally located processes found in several highly differentiated, extensively branching astrocytes $(n=2$ experiments, each observed for $30 \mathrm{~min}$ ).

\section{FURIN TREATMENT UNMASKED POTENT ENDOTHELIAL CELL INHIBITORY ACTIVITY IN DIABETIC DEMENTIA PROTEIN-A ELUATE}

Mean EC inhibitory activity in the protein-A eluates from subsets of diabetic macular edema or nephropathy $(n=6)$ or in diabetic dementia plasma $(n=5)$ significantly exceeded mean activity in protein-A eluates from diabetic non-glaucoma or glaucoma suspects (Table 3). After 9 months storage of Patient 4 and 5 diabetic dementia protein-A eluates, a significantly more inhibitory form of EC activity appeared spontaneously (Table 3) having similar magnitude to the inhibitory activity recovered from the Patient 1 diabetic dementia and glaucoma protein-A eluate following brief exposure to the proprotein convertase (PC) furin (Table 3). Mass spectrometry or amino acid sequencing of long-term stored protein-A eluates from four of four diabetic dementia plasmas tested revealed either peak $23 \mathrm{kDa}$ MW species or $86-89 \%$ amino acid sequence homology to human kappa $(\kappa)$ light chain variable regions. In an adult type one DM patient (Patient 5) who suffered a severe unremitting course of microvascular and neuropathic complications (Zimering, 2010) including multi-infarct dementia and steroid-induced glaucoma, the protein-A eluate retained its potent neurite-inhibitory activity after 5 years storage at $0-4^{\circ} \mathrm{C}$. Halfmaximal inhibition in EC survival occurred at concentrations of

Table 3 | Effect of long-term storage of protein-A eluates or furin digestion on EC activity.

\begin{tabular}{|c|c|c|c|}
\hline \multirow[t]{2}{*}{ Diabetic subset } & \multicolumn{3}{|c|}{ Endothelial cell bioactivity (\%) } \\
\hline & Before & After & $P$-value* \\
\hline \multicolumn{4}{|c|}{ LONG-TERM STORAGE (9-60 MONTHS) } \\
\hline No glaucoma or susp $(n=4)$ & $107.3 \pm 6.1$ & $108 \pm 6.3$ & 0.87 \\
\hline Glaucoma suspect $(n=4)$ & $98.7 \pm 5.3$ & $86.8 \pm 20.2$ & 0.20 \\
\hline Macular edema/nephr. $(n=6)$ & $81.2 \pm 5.8^{\dagger}$ & $86.5 \pm 14.8$ & 0.47 \\
\hline Dementia $(n=5)$ & $81.2 \pm 3.3^{\dagger}$ & $66.5 \pm 4.5(2)$ & 0.01 \\
\hline \multicolumn{4}{|l|}{ FURIN } \\
\hline $\begin{array}{l}\text { Pt 1: glaucoma + Alz dementia } \\
(n=1)\end{array}$ & $80 \pm 8$ & $65 \pm 3$ & 0.02 \\
\hline Pt 2: OHT + dementia $(n=1)$ & $82 \pm 11$ & $87 \pm 4$ & 0.63 \\
\hline
\end{tabular}

Results are mean, $\pm 1 S D$, endothelial cell bioactivity was determined as described in Section "Materials and Methods." *P-value from Student's t-test comparing results before and after storage or furin treatment ${ }^{\dagger} P<0.0001$ compared to mean activity (before storage) in group of glaucoma suspects. OHT, ocular hypertension.
Patient $5 \operatorname{IgG}(30 \mathrm{nM})$ which were comparable to the half-maximal inhibitory concentrations $(10 \mathrm{nM})$ observed in the purified monoclonal $\mathrm{IgG}_{2}$ kappa light chains obtained from a clone of human lymphoblasts (GM01500) from a patient having multiple myeloma and systemic light chain AL (data not shown). Using HS affinity chromatography, we were able to obtain a highly purified peak EC inhibitory fraction in the Patient 5 protein-A eluate which eluted from $\mathrm{HS}$ column with $0.1 \mathrm{M} \mathrm{NaCL}$. Comparison of the amino acid sequences in the Patient 5 peak, HS-purified fraction to its starting material protein-A eluate or to AL disease monoclonal $\mathrm{IgG}_{2}$ kappa light chains revealed the presence of proline at amino acid position 12 in the peak HS-purified Patient 5 diabetic eluate only. Proline at amino acid position 12 is characteristic of a restricted subgroup of kappa II gene-encoded sequences (Wu and Kabat, 1970).

\section{DISCUSSION}

The present data are the first to suggest that plasma autoantibodies from a subset of older adult type 2 diabetes having POAG or suspects cause significant inhibition of neurite outgrowth in PC 12 cells via a mechanism which may involve binding to cell surface HSPG and activation of intracellular Rho kinase. Our results are consistent in part with earlier reports of increased titers of autoantibodies specific for (optic nerve head) HSPG in subsets of normal tension or primary angle glaucoma having a systemic autoimmune disease (Tezel et al., 1999).

Unlike systemic lupus erythematosus (SLE), type 2 diabetes is not a systemic autoimmune condition. Yet autoantibodies capable of inducing EC apoptosis were described in subsets of SLE nephropathy (van Paassen et al., 2007) or in older adult type 2 diabetes in association with macular edema, nephropathy, and/or painful neuropathy (Zimering and Pan, 2009). The present finding of a significant association between the occurrence of diabetic painful neuropathy and POAG is novel. Taken together with the chlorate sensitivity of the PC12 neurite-inhibitory activity in diabetic glaucoma autoantibodies it suggests HSPG (or a closely related sulfated proteoglycan) as a possible common target for autoantibodies in diabetic POAG and diabetic painful neuropathy.

Heparan sulfate glycosaminoglycans (GAGs) play important roles in early brain development (Inatani et al., 2003) including ensuring retinal axon guidance to the optic nerve head (OgataIwao et al., 2011) and the correct topographic arrangement of axons in the optic nerve (Lee et al., 2004). HSPG are ubiquitously expressed on the cell surface of ECs, mesenchyme-derived cells and neurons. Following CNS injury, astrocyte HSPG increases its sulfation (Properzi et al., 2008). Basic fibroblast growth factor is a known neurotrophic and survival factor in RGC (Soto et al., 2006) which requires HSPG for its biological activity. Anti-HSPG autoantibodies may interfere with the survival-promoting effects of locally available bFGF in RGCs or contribute to generally low plasma bFGF in diabetic glaucoma. Autoantibody-induced neurite retraction may deprive optic axons of trophic support from postsynaptic target neurons. Reversal of astrocyte stellation in association with stress fiber expression and astrocyte contraction suggests that the diabetic glaucoma autoantibodies which induced morphological astrocyte reactivity (Tura et al., 2009) may lead to loss of glial-neuron interaction(s) which is an important source of trophic support in RGCs. 
Ten of eleven diabetic subjects who suffered POAG-related visual field loss were African-American or of Afro-Caribbean origin, groups especially prone to develop POAG or glaucomatous blindness (Marshall, 1989). Our findings of generally low plasma bFGF among diabetic glaucoma or suspects is consistent with an earlier report of a significant association between low plasma bFGF and African-American race in a multi-ethnic VADT substudy of older adults having type 2 diabetes (Zimering et al., 2008). Higher mean diastolic blood pressure in the current diabetic glaucoma group may reflect (in part) inclusion of a higher proportion of African subjects. It is also consistent with a reported association between increased diastolic blood pressure and raised IOP in older adults having diabetes (Klein et al., 1994).

The prevalence of glaucoma among blacks living in certain geographically isolated areas is striking. It suggests possible involvement of population- or race-specific hereditary predisposition factor(s). For example, in the Barbados Eye study, the prevalence of POAG among older adult Afro-Caribbean men and women (age 70 years or above) was $17 \%$; it was eight times higher than in Barbadian whites, and could not be accounted for by diabetes or hypertension (Leske et al., 1994). One possible contributory factor is known hereditable differences in autoantibody subclass concentrations. African-American children had higher concentrations of plasma total IgG and the $\operatorname{IgG}_{2}$ subclass compared to Caucasian children (Shackelford et al., 1985). Km1 is a marker in the constant region of kappa light chains which occurs with 3.7-fold higher frequency in African-American compared to Caucasian populations (Granoff et al., 1984). Km1 was associated with increased $\mathrm{IgG}_{2}$ antibody response to certain polysaccharide antigens in African-American children (Granoff et al., 1984); and the $\mathrm{IgG}_{2}$ antibody response (associated with $\mathrm{Km} 1$ ) was predominated by expression of a particular subgroup of less prevalent kappa light chain ( $\kappa$ IIa) genes (Lucas et al., 1991). A kappa II gene is predicted to have encoded the peak inhibitory kappa light chain in the eluate from (type $1 \mathrm{DM}$ ) Patient 5 having severe disease manifestations (Zimering, 2010). In contrast, in Caucasian adults, an increased $\mathrm{IgG}_{2}$ antibody response to several different common polysaccharide bacterial antigens was associated with $\mathrm{Gm} 23$, a marker in the heavy chain constant region (Ambrosino et al., 1985). Gm23 was reported to be associated with a significantly increased risk of diabetic retinopathy (Stewart et al., 1993). Our finding of a significantly increased risk for Alzheimer's dementia among the parents of diabetic glaucoma or suspects is consistent with the possibility that a subset of autoantibodies having highly potent (neurite-, EC and glial-) inhibitory properties may reflect inheritance of a particular subgroup of kappa light chain genes. Increased prevalence of such genes as the kappa II (Ig) gene subgroup in persons of African descent may reflect an earlier evolutionary selection pressure that acted to increase the prevalence of a survival-promoting, beneficial allele. The later occurrence of slow neurodegenerative diseases such as open angle glaucoma or Alzheimer's dementia in persons harboring potent kappa light chain autoantibodies is consistent with the concept of "antagonistic pleiotropy," advanced by Williams (1957). Williams postulated that senescence-associated mortality occurs through the selection of genes which confer an early reproductive (survival) benefit yet harbor additional latent harmful effects to the organism which are expressed during aging.
Glaucoma is a slowly progressive neurodegenerative disease whose severity is significantly affected by elevated IOP (Sommer, 1996; Quigley, 2011). IOP is thought to mediate remodeling of the optic nerve head extracellular matrix (ECM) in part through the activation of membrane-type matrix metalloproteinases (MTMMP) (Agapova et al., 2003). Furin is a proprotein convertase (PC) which is expressed in vascular endothelial and trabecular meshwork cells under conditions of increased hemodynamic or mechanical stress (Negishi et al., 2001; Remacle et al., 2008). In our prior work, long-term storage of certain cancer sera protein-A eluates was associated with the spontaneous appearance of highly potent EC inhibitory substances which were excitotoxic in rat embryonic hippocampal neurons and had MW and amino acid sequence characteristics of Ig kappa half-light chains (Zimering et al., 2011). The current preliminary data are consistent with the possibility that furin or a closely related PC which can recognize and cleave substrates at multi-basic amino acid sequences (Remacle et al., 2008) causes gain-in-inhibitory function through cleavage of certain IgGs at specific recognition sequences(s). One possible recognition site (perhaps giving rise to kappa halflight chains) is the $\mathrm{K}-(\mathrm{X})_{3}-\mathrm{K}-\mathrm{R}$ sequence which is located in the variable-constant switch region in certain $\kappa$ light chains. The beta site amyloid precursor protein cleaving enzyme 1 (Scholefield et al., 2003), BACE1 ( $\beta$-secretase), has been implicated in Alzheimer's disease pathogenesis because it generates amyloid $\beta$-peptide from its precursor protein. Of interest, $\beta$-secretase (BACE1) is under negative regulatory control through its binding to heparan sulfate (Scholefield et al., 2003). Certain members of the PC family are expressed at the cell surface in association with HSPG (Mayer et al., 2008). Thus localization of anti-HSPG autoantibodies at such cell regions might provide a mechanism for dual activation of $\beta$-secretase and for proteolytic processing of autoantibodies leading to more highly potent, long-lasting inhibitory substances.

A limitation of our study is that it is small and the results principally reflect the experience of older African-American men having POAG. More study in women and other racial groups is needed to confirm the present findings and to determine whether PC12 neurite-inhibitory autoantibodies may increase in non-diabetic glaucoma subjects. The mechanism(s) underlying glaucomatous neurodegeneration are complex and multifactorial (Kuehn et al., 2005). It is possible anti-HSPG autoantibodies may occur as a consequence of tissue injury yet have only a limited, bystander role in the neurodegenerative disease process. Although in vivo experimental support of a pathogenic role for anti-HSPG autoantibodies in glaucomatous neurodegeneration is lacking, in vitro effects of the autoantibodies in ECs, neurons and cerebral cortical astrocytes support a potential role in promoting neurodegeneration underlying glaucoma and dementia. Of interest, in a mouse model of hereditary glaucoma, high-dose irradiation unexpectedly completely prevented the subsequent development of glaucomatous RGC degeneration (Anderson et al., 2005). Basic FGF is released following irradiation and it protects microvascular endothelium against radiation-induced apoptosis (Fuks et al., 1994). More study in a mouse model of irradiation-induced neuroprotection could provide a test for involvement of bFGF or factors (anti-HSPG autoantibodies) which negatively affect bFGF local bioavailability in determining long-term RGC survival. Our data do not 
exclude the possible involvement of other kinds of autoreactive antibodies, such as heat shock proteins (HSP) autoantibodies, or cell-mediated immune mechanisms in retinal ganglion degeneration (Wax et al., 2008). For example, immunization with HSP 27 or HSP60 in the Lewis rat induced a glaucoma-like pattern of RGC degeneration via activation of $\mathrm{T}$ cells which secreted Fas ligand (Wax et al., 2008). Still evidence suggests that early activation of RGC survival pathways (perhaps mediated in part by bFGF) may prevent or delay Fas ligand-induced RGC apoptosis (Kim and Park, 2005).

The retinal inner limiting membrane (ILM) contains HSPG; and the ILM undergoes thickening during aging (Candiello et al., 2010) and in diabetes. In a subset of diabetic glaucoma or suspects ( 3 of 20 subjects), protein-A eluates caused mild EC stimulation suggesting that diabetic glaucomatous autoantibodies are heterogeneous and may include immune complexes. Trapping of immune complexes in the retinal ILM might disrupt its barrier function or lead to complement activation. A possible underlying role for humoral autoimmunity in subsets of dementia is suggested by reports that autoantibodies cross-reactive with vascular HSPG increased in serum from older adults having senile,

\section{REFERENCES}

Abe, K., and Misawa, M. (2003). Astrocyte stellation induced by rho kinase inhibitors in culture. Brain Res. Dev. Brain Res. 143, 99-104.

Agapova, O. A., Kaufman, P. L., Lucarelli, M. J., Gabelt, B. T., and Hernandez, M. R. (2003). Differential expression of matrix metalloproteinases in monkey eyes with experimental glaucoma or optic nerve transection. Brain Res. 967, 132-143.

Allen, C., Srivastava, K., and Bayraktutan, U. (2010). Small GTPase RhoA and its effector rho kinase mediate oxygen glucose deprivation-evoked in vitro cerebral barrier dysfunction. Stroke 41, 2056-2063.

Ambrosino, D. M., Schiffman, G., Gotschlich, E. C., Schur, P. H., Rosenberg, G. A., DeLange, G. G., et al. (1985). Correlation between $\mathrm{G} 2 \mathrm{~m}(\mathrm{n})$ immunoglobulin allotype and human antibody response and susceptibility to polysaccharide encapsulated bacteria. J. Clin. Invest. 75, 1935-1942.

Anderson, M. G., Libby, R. T., Gould, D. B., Smith, R. S., and John, S. W. (2005). High-dose radiation with bone marrow transfer prevents neurodegeneration in an inherited glaucoma. Proc. Natl. Acad. Sci. U.S.A. 102, 4566-4571.

Candiello, J., Cole, G. J., and Halfter, W. (2010). Age-dependent changes in the structure, composition and biophysical properties of a human basement membrane. Matrix Biol. 29, 402-410.
Crish, S. D., and Calkins, D. J. (2011). Neurodegeneration in glaucoma: progression and calcium-dependent intracellular mechanisms. Neuroscience 176, 1-11.

Dickson, B. J. (2001). Rho GTPases in growth cone guidance. Curr. Opin. Neurobiol. 11, 103-110.

Fillit, H. M., Kemeny, E., Luine, V., Weksler, M. E., and Zabriskie, J. B. (1987). Antivascular antibodies in the sera of patients with senile dementia of the Alzheimer's type. J. Gerontol. 42, 180-184.

Fuks, Z., Persaud, R. S., Alfieri, A., McLoughlin, M., Ehleiter, D., Schwartz, J. L., et al. (1994). Basic fibroblast growth factor protects endothelial cells against radiationinduced programmed cell death in vitro and in vivo. Cancer Res. 54, 2582-2590.

Goldacre, M. J., Wotton, C. J., and Keenan, T. D. (2012). Risk of selected eye diseases in people admitted to hospital for hypertension or diabetes mellitus: record linkage studies. $\mathrm{Br}$. J. Ophthalmol. 96, 872-876.

Granoff, D. M., Pandey, J. P., Boies, E., Squires, J., Munson, R. S., and Suarez, B. (1984). Response to immunization with Haemophilus influenzae type $\mathrm{b}$ polysaccharidepertussis vaccine and risk of Haemophilus meningitis in children with the $\mathrm{Km}(1)$ immunoglobulin allotype. J. Clin. Invest. 74, 1708-1714.

Hoogewerf, A. J., Cisar, L. A., Evans, D. C., and Bensadoun, A. (1991).

Alzheimer's type dementia (Fillit et al., 1987). Brain tissue from Alzheimer's-type dementia patients showed diffuse deposition of IgG, fibrinogen, and glial hyperreactivity indicative of loss of EC barrier integrity (Ryu and McLarnon, 2009). More study is needed to determine whether plasma diabetic autoantibody PC12 neurite-inhibitory activity may be a useful (early) marker for sustained activation of Rho kinase in diverse cell types including neurons, astrocytes, or ECs involved in mediating slowly, progressive glaucomatous visual field loss, or in a subset of diabetes having dementia.

\section{ACKNOWLEDGMENTS}

We thank Dr. Carlos Abraira, and Dr. William Duckworth, VADT Co-Chairmen for their support. We thank Dr. Cheryl Dreyfus and Dr. Janet Alder, Department of Neuroscience and Cell Biology, UMDNJ-Robert Wood Johnson Medical School for generously providing cerebral cortical astrocytes used in these experiments. This study was supported by a grant (to Mark B. Zimering) from the Veterans Biomedical Research Institute, East Orange, NJ, USA; and by the Department of Veterans Affairs Cooperative Studies Program, Office of Research and Development, Washington, DC.

Effect of chlorate on the sulfation of lipoprotein lipase and heparan sulfate proteoglycans. Sulfation of heparan sulfate proteoglycans affects lipoprotein lipase degradation. J. Biol. Chem. 266, 16564-16571.

Inatani, M., Irie, F., Plump, A. S., Tessier-Lavigne, M., and Yamaguchi, Y. (2003). Mammalian brain morphogenesis and midline axon guidance require heparan sulfate. Science 302, 1044-1046.

Ishizaki, T., Uehata, M., Tamechika, I. Keel, J., Nonomura, K., Maekawa M., et al. (2000). Pharmacological properties of Y-27632, a specific inhibitor of rho-associated kinases. Mol. Pharmacol. 57, 976-983.

Kameda, T., Inoue, T., Inatani, M. Fujimoto, T., Honjo, M., Kasaoka, N., et al. (2012). The effect of Rho-associated protein kinase inhibitor on monkey Schlemm's canal endothelial cells. Invest. Ophthalmol. Vis. Sci. 53, 3092-3103.

Kim, H. S., and Park, C. K. (2005). Retinal ganglion cell death is delayed by activation of retinal intrinsic cell survival program. Brain Res. 1057, 17-28.

Klein, B. E., Klein, R., and Jensen, S. C. (1994). Open-angle glaucoma and older-onset diabetes. The Beaver Dam Eye Study. Ophthalmology 101, 1173-1177.

Kuehn, M. H., Fingert, J. H., and Kwon, Y. H. (2005). Retinal ganglion cell death in glaucoma: mechanisms and neuroprotective strategies. Ophthalmol. Clin. North Am. 18, 383-395.
Kumar, J., and Epstein, D. L. (2011). Rho GTPase-mediated cytoskeletal organization in Schlemm's canal cells play a critical role in the regulation of aqueous humor outflow facility. $J$. Cell. Biochem. 112, 600-606.

Lee, J. S., von der Hardt, S., Rusch, M. A., Stringer, S. E., Stickney, H. L., Talbot, W. S., et al. (2004). Axon sorting in the optic tract requires HSPG synthesis by ext2 (dackel) and extl3 (boxer). Neuron 44, 947-960.

Leske, M. C., Connell, A. M., Wu, S. Y., Hyman, L. G., and Schachat, A. P. (1994). Risk factors for open-angle glaucoma. The Barbados Eye Study. Ophthalmology 101, 1173-1177.

Lucas, A. H., Langley, R. J., Granoff, D. M., Nahm, M. H., Kitamura, M. Y., and Scott, M. G. (1991). An idiotypic marker associated with a germ-line encoded kappa light chain variable region that predominates the vaccine-induced human antibody response to the Haemophilus influenzae b polysaccharide. J. Clin. Invest. 88, 1811-1818.

Marshall, E. C. (1989). Racial differences in the presentation of chronic open-angle glaucoma. J. Am. Optom. Assoc. 60, 760-767.

Mayer, G., Hamelin, J., Asselin, M. C., Pasquato, A., Marcinkiewicz, E., Tang, M., et al. (2008). The regulated cell surface zymogen activation of the proprotein convertase PC5A directs the processing of its secretory substrates. J. Biol. Chem. 283, 2373-2384. 
Negishi, M., Lu, D., Zhang, Y. Q., Sawada, Y., Sasaki, T., Kayo, T., et al. (2001). Upregulatory expression of furin and transforming growth factor-beta by fluid shear stress in vascular endothelial cells. Arterioscler. Thromb. Vasc. Biol. 21, 785-790.

Ogata-Iwao, M., Inatani, M., Iwao, K., Takihara, Y., Nakaishi-Fukuchi, Y., Irie, F., et al. (2011). Heparan sulfate regulates intraretinal axon pathfinding by retinal ganglion cells. Invest. Ophthalmol. Vis. Sci. 52, 6671-6679.

Properzi, F., Lin, R., Kwok, J., Naidu, M., van Kuppevelt, T. H., Ten Dam, G. B., et al. (2008). Heparan sulphate proteoglycans in glia and in the normal and injured CNS: expression of sulphotransferases and changes in sulphation. Eur. J. Neurosci. 27, 593-604.

Quigley, H. A. (2011). Glaucoma. Lancet 377, 1367-1377.

Remacle, A. G., Shiryaev, S. A., Oh, E. S., Cieplak, P., Srinivasan, A., Wei, G., et al. (2008). Substrate cleavage analysis of furin and related proprotein convertases. A comparative study. J. Biol. Chem. 283, 20897-20906.

Ryu, J. K., and McLarnon, J. G. (2009). A leaky blood-brain barrier, fibrinogen infiltration and microglial reactivity in inflamed Alzheimer's disease brain. J. Cell. Mol. Med. 13, 2911-2925.

Scholefield, Z., Yates, E. A., Wayne, G., Amour, A., McDowell, W., and Turnbull, J. E. (2003). Heparan sulfate regulates amyloid precursor protein processing by BACE1, the Alzheimer's beta-secretase. J. Cell Biol. 163, 97-107.

Shackelford, P. G., Granoff, D. M., Nahm, M. H., Scott, M. G., Suarez, B., Pandey, J. P., et al. (1985). Relation of age, race, and allotype to immunoglobulin subclass concentrations. Pediatr. Res. 19, 846-849.
Sommer, A. (1996). Glaucoma risk factors observed in the Baltimore Eye Survey. Curr. Opin. Ophthalmol. 7, 93-98.

Soto, I., Rosenthal, J. J., Blagburn, J. M., and Blanco, R. E. (2006). Fibroblast growth factor 2 applied to the optic nerve after axotomy up-regulates BDNF and TrkB in ganglion cells by activating the ERK and PKA signaling pathways. J. Neurochem. 96, 82-96.

Stewart, L. L., Field, L. L., Ross, S. and McArthur, R. G. (1993). Genetic risk factors in diabetic retinopathy. Diabetologia 36, 1293-1298.

Tamura, H., Kawakami, H., Kanamoto, T., Kato, T., Yokoyama, T., Sasaki, K., et al. (2006). High frequency of open-angle glaucoma in Japanese patients with Alzheimer's disease. J. Neurol. Sci. 246, 79-83.

Tezel, G., Edward, D. P., and Wax, M. B. (1999). Serum autoantibodies to optic nerve head glycosaminoglycans in patients with glaucoma. Arch. Ophthalmol. 117, 917-924.

Tezel, G., and Wax, M. B. (2004). The immune system and glaucoma. Curr. Opin. Ophthalmol. 15, 80-84.

Tura, A., Schuettauf, F., Monnier, P. P., Bartz-Schmidt, K. U., and HenkeFahle, S. (2009). Efficacy of Rhokinase inhibition in promoting cell survival and reducing reactive gliosis in the rodent retina. Invest. Ophthalmol. Vis. Sci. 50, 452-461.

Uehata, M., Ishizaki, T., Satoh, H., Ono, T., Kawahara, T., Morishita, T., et al. (1997). Calcium sensitization of smooth muscle mediated by a Rhoassociated protein kinase in hypertension. Nature 389, 990-994.

van Paassen, P., Duijvestijn, A., Debrus-Palmans, L., Damoiseaux, J., Vroomen, M., and Tervaert, J. W. (2007). Induction of endothelial cell apoptosis by IgG antibodies from SLE patients with nephropathy: a potential role for anti-endothelial cell antibodies. Ann. N. Y. Acad. Sci. 1108, 147-156.

Wax, M. B., Tezel, G., Yang, J., Peng, G., Patil, R. V., Agarwal, N., et al. (2008). Induced autoimmunity to heat shock proteins elicits glaucomatous loss of retinal ganglion cell neurons via activated T-cell-derived fasligand. J. Neurosci. 28, 12085-12096.

Williams, G. C. (1957). Pleiotropy, natural selection, and the evolution of senescence. Evolution 11, 398-411.

Wu, T. T., and Kabat, E. A. (1970) An analysis of the sequences of the variable regions of Bence Jones proteins and myeloma light chains and their implications for antibody complementarity. J. Exp. Med. 132, 211-250.

Zimering, M. B. (2010). Recurrent macular edema and stroke syndrome in type 1 diabetes mellitus with potent endothelial cell inhibitory autoantibodies. Endocr. Pract. 16, 842-850.

Zimering, M. B., Alder, J., Pan, Z., and Donnelly, R. J. (2011). Anti-endothelial and anti-neuronal effects from auto-antibodies in subsets of adult diabetes having a cluster of microvascular complications. Diabetes Res. Clin. Pract. 93, 95-105.

Zimering, M. B., Anderson, R. J., Luo, P., Moritz, T., and VADT Investigators (2008). Plasma basic fibroblast growth factor is correlated with plasminogen activator inhibitor-1 concentration in adults from the Veterans Affairs Diabetes Trial. Metab. Clin. Exp. 57, 1563-1569.

Zimering, M. B., Anderson, R. J., Moritz, T. E., Ge, L., and Investigators for the VADT. (2009a). Low plasma basic fibroblast growth factor is associated with laser photocoagulation treatment in adult type 2 diabetes mellitus from the Veterans Affairs Diabetes Trial. Metab. Clin. Exp. 58, 393-400.
Zimering, M. B., Anderson, R. J., Moritz, T. E., Ge, L., and VADT Investigators (2009b). Endothelial cell inhibitory auto-antibodies are associated with laser photocoagulation in adults from the Veterans Affairs Diabetes Trial. Metab. Clin. Exp. 58, 882-887.

Zimering, M. B., and Pan, Z. (2009). Autoantibodies in type 2 diabetes induce stress fiber formation and apoptosis in endothelial cells. J. Clin. Endocrinol. Metab. 94, 2171-2177.

Zimering, M. B., and Thakker-Varia, S. (2002). Increased fibroblast growth factor-like autoantibodies in serum from a subset of patients with cancer-associated hypercalcemia. Life Sci. 71, 2939-2959.

Conflict of Interest Statement: The authors declare that the research was conducted in the absence of any commercial or financial relationships that could be construed as a potential conflict of interest.

Received: 25 March 2013; paper pending published: 18 April 2013; accepted: 01 May 2013; published online: 15 May 2013.

Citation: Zimering MB, Moritz TE and Donnelly RJ (2013) Anti-neurotrophic effects from autoantibodies in adult diabetes having primary open angle glaucoma or dementia. Front. Endocrinol. 4:58. doi: 10.3389/fendo.2013.00058 This article was submitted to Frontiers in Diabetes, a specialty of Frontiers in Endocrinology.

Copyright (c) 2013 Zimering, Moritz and Donnelly. This is an open-access article distributed under the terms of the Creative Commons Attribution License, which permits use, distribution and reproduction in other forums, provided the original authors and source are credited and subject to any copyright notices concerning any third-party graphics etc. 